\title{
К ВОПРОСУ О РАЗРАБОТКЕ ОРФОГРАФИЧЕСКИХ НОРМ МЛАДОПИСЬМЕННЫХ ДАГЕСТАНСКИХ ЯЗЫКОВ
}

\section{ON THE DEVELOPMENT OF ORTHOGRAPHIC NORMS OF THE YOUNG WRITTEN DAGESTANI LANGUAGES \\ M. Ibragimova S. Mallaeva}

Summary: The article formulates the general provisions that were the result of the analysis of the state of development of the spelling norms of Agul, Rutul and Tsakhur, which received the status of written in 1990. The aim was to establish the current state and forecast the prospects for the development and improvement of orthographic codes of young written languages.

It is established that the collection of spelling rules is included in the Rutul-Russian dictionary, one of the Agul-Russian dictionaries contains a draft of the code, and this section is not included in the Tsakhur-Russian dictionary. In this regard, native speakers of young written languages will need to turn to the dictionary spelling before the adoption and publication of spelling norms, and in the case of the Rutul language before their unification.

Keywords: young written languages, Agul language, Rutul language, Tsakhur language, spelling.
Ибрагимова Мариза Оглановна

Д.филол.н., дочент, в.н.с., Институт языка, литературы и искусства Дагестанского федерального исследовательского чентра РАН (г. Махачкала), mariza71@mail.ru

Маллаева Светлана Джавадовна

К.филол.н., дочент, н.С., Институт языка, литературы и искусства Дагестанского федерального исследовательского чентра РАН (г. Махачкала), mallaeva777@mail.ru

Аннотация: В статье сформулированы общие положения, явившиеся результатом анализа состояния разработанности орфографических норм трёх дагестанских языков, получивших статус письменных в 1990 году, - агульского, рутульского и цахурского, с целью установления современного состояния и прогнозирования перспектив разработки и совершенствования орфографических сводов младописьменных языков. Установлено, что свод орфографических правил включен в рутульско-русский словарь, один из агульско-русских словарей содержит проект свода, в цахурско-русском словаре этот раздел отсутствует. В связи с этим носителям младописьменных языков необходимо будет обращение к словарному написанию до момента принятия и издания орфографических норм, а в случае с рутульским языком - до их унификации.

Ключевые слова: младописьменные языки, агульский язык, рутульский язык, цахурский язык, орфография.

стали вестись на русском языке [Ибрагимов, 2004: 8]. До перехода в 1957 на русский язык, в агульских школах языком обучения являлся лезгинский [Мазанаев Ш.А., 2017 , с. 3].

Агульский алфавит, составленный Ш.А. Мазанаевым и И.А. Мазанаевым на основе собственно агульского диалекта, включает 53 графемы:

A а, Б б, В в, Г г, Гъгъ, Гьгь, ГІ гІ, Д д, Дж дж, Е е, Ё ё, Ж ж, 3з, Ии, Й й, К к, КК кк, КъКъ, Кькь, KІ кl, Л л, М м, Н н, О о, Пп, ПП пп, ПІ пl, Р p, Сс, Т т, ТТ тт, ТІ тl, У у, Уь уь, Ф $\phi, X x, X_{ъ} ъ$,

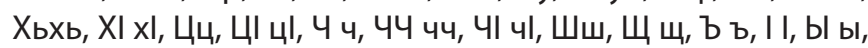
b ь, Э э, Ю ю, Я Я.

Рутульский алфавит, составленный К.Э. Джамаловым и Ф.И. Гусейновой на основе мухадского диалекта, включает 50 графем:

A a, Al al, Б б, В в, Г г, Гъгъ, Гьгь, ГІ гl, Д д, Дж дж, E e, Ё ё, Ж ж, 3з, Ии, Й й, К к, КъКъ, КьКь, КІ кl, Л л, М м, Н н, О о, Пп, ПI пl, Р p, Сс, Т т, TI тl, У y, УІ yl, Уьуь, Ф ф, Х x, ХъXъ, Хьхь, Цц, Цا цا, ૫ ч, Чા чl, Шш, щ щ, ъ ъ, Ы ы, bll ыl, b ь, Э э, Ю ю, Я я.

Цахурский алфавит составлен на основе цахского
До 1952 года в рутульских и цахурских школах языком обучения являлся азербайджанский, затем занятия
Предпринятая А.Н. Генко в начале 30-х гг. попытка составления алфавита для рутульского языка не увенчалась успехом [Сергеева, 1989, с. 119].

ком обучения являлся азербаиджанскии, затем занятия

Серия: Гуманитарные науки №6 июнь 20212. 
диалекта Г.Х. Ибрагимовым и Н.Г. Исаевым, он включает 50 графем:

A a, Al al, Б б, В в, Г г, Гъ гъ, Гь гь, ГІ гl, Д д, Дж дж, E e, Ё ё, Ж ж, 3 з, Ии, Й й, К к, Къ Къ, Кькь, КІ кl, Лл, М м, Н н, О о, Оьоь, П п, ПІ пl, Р p, Сc, Т т, TI Tl, У y, Уl yl, Ф ф, X x, Xъ xъ, Хь хь, Ц ц, ЦІ цl, ч ч, ЧІ чl, Ш ш, Щ щ, ъ ъ, Ы ы, bll ыl, b b, Э э, Ю ю, Я я.

Альтернативный цахурский алфавит на основе латиницы был принят в 1996 году в Азербайджане. В том же году был издан букварь на латинице [Qarayev A., 1996].

С 1991-1992 гг. в школах Агульского и Рутульского районов родные языки преподаются как учебные предметы. К настоящему времени на этих языках издана учебная литература для начальной школы.

За три десятилетия, прошедшие со времени принятия алфавитов, сделано немало для приведения языков в соответствие статусу государственного языков и вовлечения их в процесс полноценного функционирования: издаются республиканские газеты на агульском, рутульском и цахурском языках - «Агьуларин хабарар» («Вести Агула»), «МыхаІбишды цlинды хабарбыр» («Рутульские новости»), «Нур» («Свет»), раз в месяц на младописьменных языках транслируются передачи на дагестанском телевидении, постепенно формируется художественная и учебная литература на трёх языках, что способствует становлению литературных норм.

При этом графика и орфография младописьменных языков чаще становятся объектом изучения специалистов - лингвистов, журналистов, учителей школ, у молодого поколения интерес к родному языку отсутствует, что вызывает беспокойство.

Ситуация с популяризацией младописьменных языков, распространением письменности, разработкой норм орфографии и орфоэпии усугубляется отсутствием перспектив использования полученных знаний по родному языку: вузы республики постепенно отказываются от подготовки учителей по языкам малочисленных народов в связи с трудностями в формировании языковых групп и нежеланием оплачивать труд преподавателей групп из 3-5 студентов.

Поправки в п. 14 Закона «Об образовании в Российской Федерации» в части изучения родного языка [2012], предполагающие выбор языка, который учащиеся будут изучать в школе в качестве родного, способствовали ослаблению позиций некоторых дагестанских языков, так как в районах республики, где проживают носители младописьменных и бесписьменных языков, предпочтение будет отдано русскому языку (как родному), в целях дополнительной подготовки к обязательному ЕГЭ.

Среди причин неактивного распространения и употребления письменности не последнее место занимает и сложность графической системы, разработанной для агульского, рутульского и цахурского языков. Несовершенство принятых алфавитов и трудности в их применении на практике обусловлены тем обстоятельством, что в целях адаптации новых алфавитов к полиграфической базе издательств Республики Дагестан составители алфавита были ограничены выбором наиболее доступных форм передачи звукового состава языка посредством знаков кириллицы.

Мониторинг мнений лингвистов, поэтов, писателей, учителей родного языка, работников СМИ позволил нам выявить наиболее актуальные проблемы, связанные с особенностями алфавитов и осложняющие обучение письму и чтению на младописьменных языках:

1. громоздкость алфавита, обусловленная наличием в алфавите диграфов, состоящих из двух знаков: al (в рутульском и цахурском алфавитах), гъ, гь, гl, дж, кк (в агульском алфавите), къ, кь, кl, оь (в цахурском алфавите), пп (в агульском алфавите), пl, тт (в агульском алфавите), тl, yl (в рутульском и цахурском алфавитах), уь, хъ, хь, xl, цl, чч (в агульском алфавите), чl, ыl (в рутульском и цахурском алфавитах);

2. отсутствие ряда графем в официально утвержденных алфавитах:

- отсутствие умляутированной гласной $а ь$ не позволяет носителям рутульского и цахурского языков отражать соответствующий звук на письме в рутульских словах гаьш «голод», баьл «лоб», баьли «вишня», в цахурских словах чlаьр «волос», ваьш «сто», маьг «челка» и т.д. (при этом умляутированная графема уь составителями включена в алфавиты);

- отсутствие графемы дз в алфавите при её наличии в рутульском языке: дзыр «стекло, медь», дзыдзя/хъ «муравей», дзирдзем «цепь» и т.д.;

- отсутствие графемы, передающей фарингальный звук $x l$, в рутульском алфавите вызывает необходимость использования комплекса звуков - ларингального гь в совокупности с фарингализованным гласным;

3. передача фарингализации в рутульском и цахурском языках гласными al, yl, bl, что не является нормой для других дагестанских алфавитов; для передачи фарингализации в агульский алфавит включены фарингализованные согласные I, zl, xl;

4. наличие в рутульском и цахурском языках долгих гласных aa, yy, blы, alal, ylyl, bl/ыl, не зафиксированных в алфавите, но имеющих смыслоразличительную функцию: рут.: хала «в доме, в дом» - халаа «из дома», мукъаl «в селе, в село» - мукъalal «из села» и т.д.; цах.: гаде «мальчик» - гадее (форма эргатива); гьохас «бегать» (форма I, IV классов) - гьоохас (форма III класса) и т.д.;

5. употребление знака ъ между двумя идентичными соседствующими гласными в исследуемых языках 
в целях дифференциации долгих и повторяющихся гласных: агул.: халаъас «из дома», ракаъас «с улицы»; рут.: лыъын «надевать», гываъан «вязаный носок»; цах.: гъаъас «делать», саъас «собирать» и т.д.;

6. введение в агульский алфавит графем кк, nn, mm, чч для передачи геминации: ккул «тулуп», тmур «ложка», ппази «сокол».

При этом в алфавиты трех языков включены графемы $\ddot{e}, ю, я, m, b$, необходимые, как правило, только для передачи заимствований-русизмов. Буква о в агульском и рутульском языках также используется только в заимствованиях, в отличие от цахурского языка, в котором она передает активно функционирующий в языке звук [о].

Для преодоления проблемы неполного соответствия звукового состава языка официальному алфавиту в рутульский букварь «Алифба» К.Э. Джамаловым и С.М. Мaхмудовой была включена графема дз [1992]. В научных работах Г.Х. Ибрагимова по цахурскому и рутульскому языкам также употребляются буквы аь и дз. [1990; 2004].

В «Рутульско-русском словаре» К.Э. Джамалова и С.А. Семедова, написанном на основе ихрекского диалекта [2006], и в «Русско-рутульском словаре» Э.И. Исмаиловой [2011] даны словарные статьи на буквы $а$ ь и дз. В «Рутульско-русский словарь» А.С. Алисултанова и Т.А. Сулеймановой для обеспечения полноценной передачи звукового состава языка включены графемы $a b$, дз и $x l$ [2019].

Составитель «Агульско-русского словаря» М.Р. Рамазанов, напротив, упростил подачу лексического материала, не включив словарные статьи с начальными графемами дж, кк, nn, mm, чч [2010]. В «Русско-агульский. Агульско-русский словарь» Ш.А. Мазанаева включены словарные статьи с геминированными начальными графемами [2017].

Актуальной задачей остается разработка орфографических норм, обязательных для всех пишущих на младописьменных языках, так как их отсутствие усложняет задачи овладения письмом и порождает многочисленные варианты написания одной и той же словоформы.

Для рутульского языка эта задача была выполнена А.С. Алисултановым и Т.А. Сулеймановой - авторами «Рутульского-русского словаря», к которому приложен «Свод орфографических правил» на рутульском и русском языках, одновременно являвшийся и руководством для составления словаря [2019, с 491-518].

Составитель агульского орфографического словаря М.Р. Рамазанов включил в словарь под авторской редакцией проект «Правил правописания агульского языка», не обсужденный со специалистами по агульскому языку и не принятый на официальном уровне [2015, с. 387-405].
Орфографическая система младописьменных языков складывается параллельно с их развитием. При этом ее нормы не всегда отражают динамику развития языков, чем и обусловлено неполное соответствие фонетической грамматической систем исследуемых языков.

В связи с тем, что орфографические своды для исследуемых языков находятся на стадии разработки или совершенствования, бытует употребление параллельных орфографических вариантов, обусловленное разными факторами: руководством либо фонетическим, либо морфологическим принципом при передаче идентичных морфем; разницей в понимании морфемного членения некоторых слов; особенностями передачи на письме заимствований, связанными с наличием фонетически неравноценных диалектных когнатов-арабизмов, разницей в передаче русизмов раннего и позднего хронологических уровней: истакан «стакан» (рут., цах.)// истикан (агул.), уст/ул «стол, стул» (рут., агул.)// устул (цах.), но компьютер, телевизор и т. д.

Разработанный специалистами для регламентирования и упорядочения рутульского правописания свод правил охватывает не все случаи спорных написаний, в некоторых случаях необходимо будет обращение к словарному написанию, что актуально и для носителей агульского и цахурского языков до момента издания свода орфографических норм.

При составлении и дальнейшей унификации орфографических норм следует руководствоваться принципами выбора написания, в большей мере соответствующего системе современных младописьменных языков, учитывая и орфоэпическую традиции, складывавшиеся у носителей языков веками, выбирая, например первый из вариантов винтуфка и винтовка (рут.), къайфат и конфета (агул.), филтир и фильтр (цах.), несмотря на несовпадение графем с языком-первоисточником.

Руководствуясь опытом разработки правил орфографии языков с богатой письменной традицией, при параллельном употреблении слов и морфем следует преимущественно сохранить написание, соответствующее морфологическому принципу; например, из написаний куут/кьун и куудкьун «оторвать что-либо» (рут.), киn/mluн и кибтluн «привязать кого-, что-либо» (рут.), алеn/mle и алебтlе «бери» (цах.), кlеuйтхьу и кlеийдхьу «падать» (цах.) правильными будут вторые варианты с маркерами классов -д- и -б-. После обсуждения и принятия правила орфографии целесообразно постепенно вводить в программу каждого класса, учитывая знания и возможности учащихся.

Использование орфографических норм работниками средств массовой информации на младописьменных языках позволит донести их до сознания носителей с целью дальнейшего использования на практике. 


\section{ЛИТЕРАТУРА}

1. Алисултанов А.С., Сулейманова Т.А. Рутульско-русский словарь. - Махачкала: АЛЕФ, 2019.

2. Джамалов К.Э., Семедов С.А. Рутульско-русский словарь (ихрекский диалект). - М., 2006.

3. Джамалов К.Э., Махмудова С.М. Алифба. - Махачкала, 1992.

4. Ибрагимов Г.Х. Цахурский язык. - М., 1990.

5. Ибрагимов Г.Х. Рутульский язык: Синхрония и диахрония. - Махачкала, 2004.

6. Ибрагимов Г.Х., Нурмамедов Ю.М. Цахурско-русский словарь. - Махачкала: ИЯЛИ ДНЦ РАН, 2010. 532 с.

7. Исмаилова Э.И. Русско-рутульский словарь. - Махачкала, 2011.

8. Мазанаев Ш.А. Русско-агульский словарь. Махачкала: Издательство ДГУ, 2012. 132 с.

9. Мазанаев Ш.А. Агульско-русский словарь. - Махачкала: Издательство ДГУ, 2014. 182 с.

10. Мазанаев Ш.А. Русско-агульский словарь. Агульско-русский словарь. - Махачкала: Издательство ИП Хайбуллина Ф.Ф., 2017. 300 с.

11. Рамазанов М.Р. Агульско-русский словарь. - Махачкала: Издательство «Лотос», 2010.712 с.

12. Рамазанов М.Р. Агъул чІалан орфографияйнин словарь. - Махачкала: ИП Бисултанова П.Ш., 2015. 418 с. (На агульском языке).

13. Сергеева Г.А. Межэтнические связи народов Дагестана во второй половине XIX-XX вВ. (этноязыковые аспекты)//Кавказский этнографический сборник. Изд-во Академии наук СССР, 1989. Т. 9.

14. Федеральный закон «0б образовании в Российской Федерации» 0т 29.12.2012. N 273-Ф3

15. Qarayev A. AIlifbey. - Bakı: Maarif nəşriyyatı, 1996.

( ) Ибрагимова Мариза Оглановна (mariza71@mail.ru), Маллаева Светлана Джавадовна (mallaeva777@mail.ru).

Журнал «Современная наука: актуальные проблемы теории и практики»

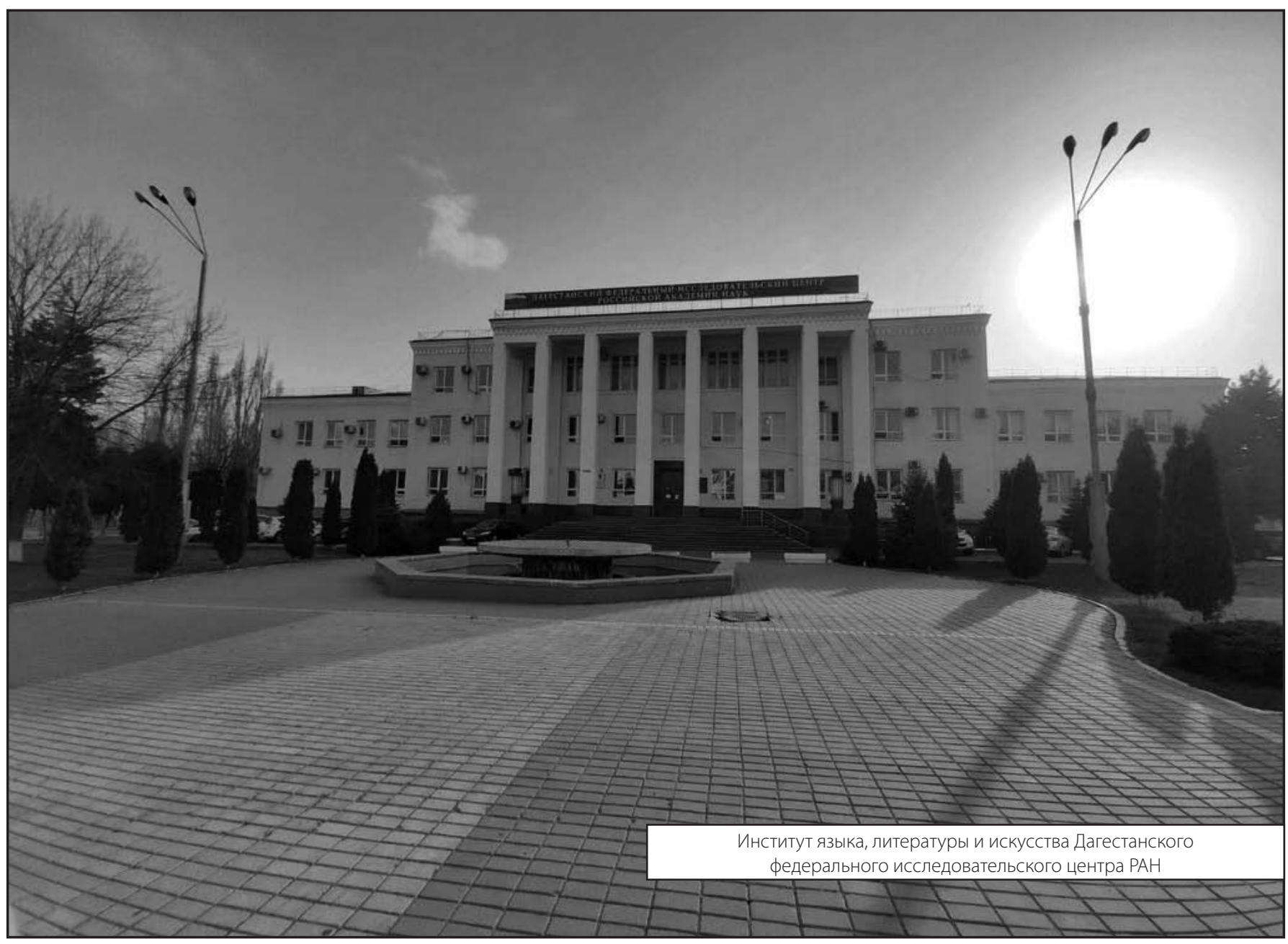

